\title{
Microscopic Identification of Micro-Organisms on Pre-Viking Swedish Hillfort Glass
}

Jamie L. Weaver ${ }^{1}$, Carolyn I. Pearce ${ }^{2}$, Bruce Arey ${ }^{2}$, Michele Conroy ${ }^{2}$, Edward P. Vicenzi ${ }^{3}$, Rolf Sjoblom ${ }^{4}$, Robert J. Koestler ${ }^{3}$, Paula T. DePriest ${ }^{3}$, Thomas F. Lam ${ }^{3}$, David K. Peeler ${ }^{2}$, John S. McCloy ${ }^{5}$, and Albert A. Kruger ${ }^{6}$

1. National Institute of Standards and Technology, Gaithersburg, USA.

2. Pacific Northwest National Laboratory, Richland, USA.

3. Museum Conservation Institute, Smithsonian Institution, Suitland, USA.

4. Luleå University of Technology, Luleå, Sweden.

5. School of Mechanical and Materials Engineering, Washington State University, Pullman, USA.

6. Department of Energy, Office of River Protection, Richland, USA.

Broborg Hillfort is a vitrified hillfort located in the Husby-Långhundra parish in Uppland Sweden (Fig. 1A). The site dates to the Great Migration Period, around $740 \pm 100 \mathrm{CE}$. [1]. Two types of glasses have been identified within the ramparts - one that is rich in $\mathrm{Si}$ and one that is rich in $\mathrm{Fe}$ [2]. Both glasses have been found on the outside surface of the walls, and have been exposed to atmosphere since their vitrification (Fig. 1B). Given these conditions, and their reported chemical compositions, the two glasses have been determined to be candidates for the study of the long-term alteration of silicate glasses in natural environments [3]. A unique aspect of the alteration research on these samples has been the use of microscopy to identify microbial activity on the surface of the glasses (Fig. 2 A-I). This presentation discusses how measurements of these species were made, and special techniques developed and used during sample preparation and data acquisition.

In this presented study, the surface of a specimen excavated from Broborg (Fig. 1C) was imaged in a FEI Helios NanoLab 660 (Hillsboro, OR) FIB-SEM with an Energy Dispersive Spectrometer (EDS) (EDAX Newark, NJ). An accelerating voltage of $5 \mathrm{keV}$ for imaging, 10 or $20 \mathrm{keV}$ for EDS (dependent chemistry/biochemistry of site), and a working distance of $4 \mathrm{~mm}$ were used in the analyses. Imaging was performed with an Everhart-Thornley secondary electron (SE) detector in field-free conditions, and through-the-lens detectors (TLD) for SE and back-scatter electron (BSE) imaging in immersion mode. Both glass and mineral sections of the sample were studied.

Certain commercial products are identified in this paper to specify the experimental procedures in adequate detail. This identification does not imply recommendation or endorsement by the authors or by the National Institute of Standards and Technology or Department of Energy, nor does it imply that the products identified are necessarily the best available for the purpose. Contributions of the Department of Energy and National Institute of Standards and Technology are not subject to copyright.

References:

[1] P. Kresten et al. Geochronometria, 22 (2003), p. 9.

[2] P. Kresten et al. Geologiska Föreningen i Stockholm Förhandlingar, 115 (1993), p. 13.

[3] R Sjöblom, H Ecke, \& E Brännvall, Intl. J. Sust. Dev. Planning (2013). 

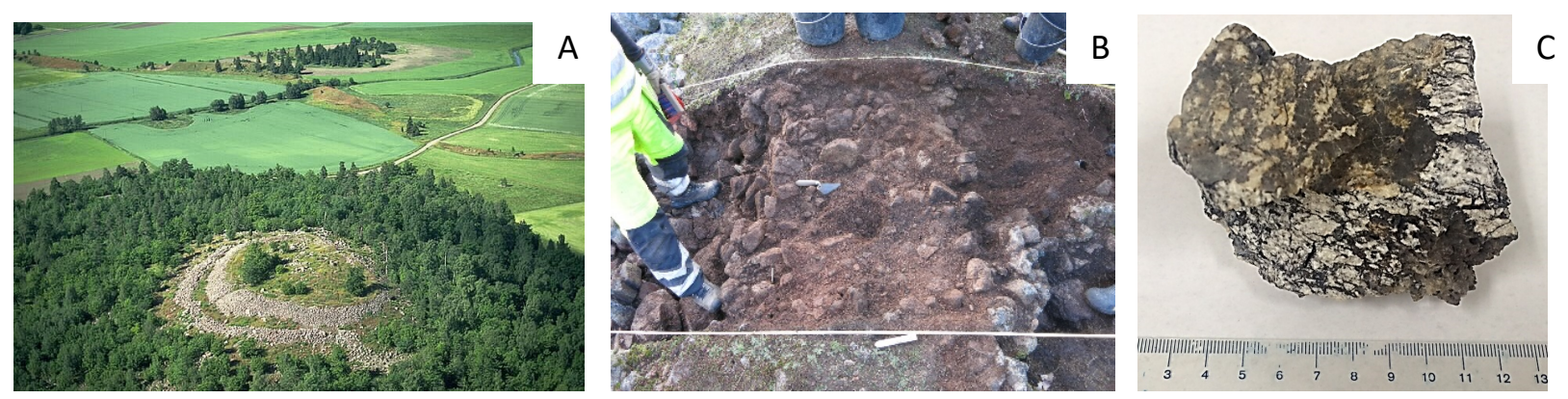

Figure 1. A) An arial view of Broborg. B) Excavation at Broborg, Fall 2017. C) Specimen of vitrified material analyzed in this study.
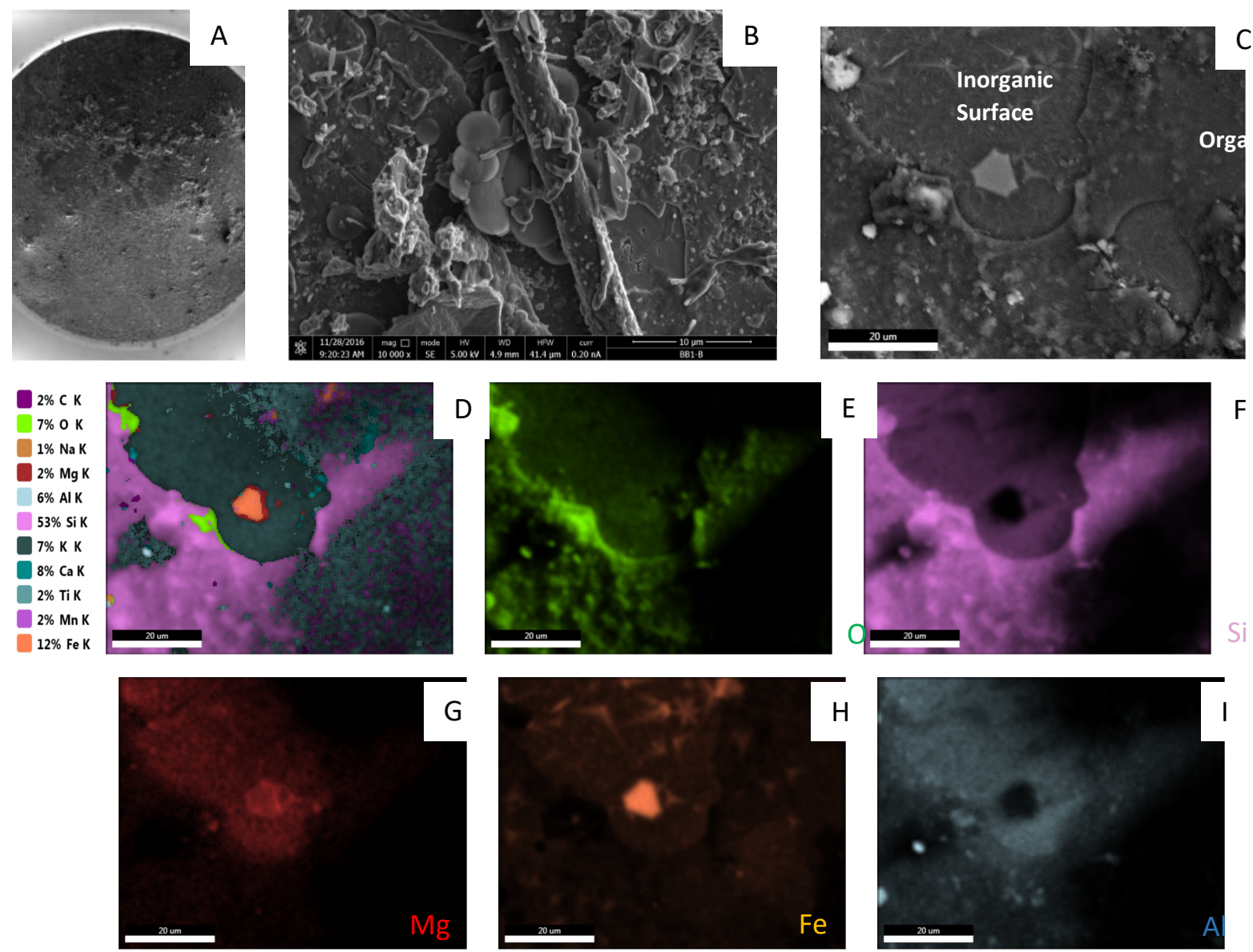

Figure 2. A) Low magnification image of glass sample with organics on the surface. B) High magnification image of glass surface with organics anpd microbes. C - I) SEM and EDS images of crystal in the high Fe glass matrix. D) is a composite image of SEM image and EDS maps for several elements measured for this sample area. 